\title{
Industrieforum-Industrial Forum
}

Neu: Ren-o-vit wasserlösliche Vitamine für Nierenkranke

Bei Patienten mit chronischer Niereninsuffizienz kommt es häufïg zu einem Mangel an wasserlöslichen Vitaminen

aufgrund einer verminderten Zufuhr von wasserlöslichen Vitaminen durch diätetische

Restriktion kaliumreicher Nahrungsmittel, die gleichzeitig wertvolle Vitaminträger sind (Milch, Obst, Gemüse, Fleisch, Brot) und/oder

durch Verluste wasserlöslicher und dadurch dialysabler Vitamine durch Dialysebehandlung. Ren-o-vit ist ein speziell nach den Bedürfnissen Nierenkranker ent-wickeltes Vitaminpräparat zur ergänzenden diätetischen Behandlung von Niereninsuffizienz. Die Zusammensetzung entspricht den Emp-fehlungen der NIH-Study Group (National Institute of Health: Modification of Diet in Renal Disease, MDRD. Protocol Phase III, 1988) über den zusätzlichen Vitaminbedarf bei Niereninsuffizienz. Ren-o-vit enthält alle wasserlöslichen Vitamine ink1. Vitamin B12. Fettlösliche Vitamine (Vitamin A, D, E) sind nicht enthalten, da bei Niereninsuffizienz im allgemeinen kein zusätzlicher Bedarf besteht, darüber hinaus die Gefahr toxischer Akkumulation fettlöslicher Vitamine bei eingeschränkter Nierenfunktion gegeben ist. Der Gehalt an Ascorbinsäure (Vitamin C) in einem Dragee liegt un-ter den Empfehlungen der Deutschen Gesellschaft für Ernährung (DGE) über die Höhe der täglichen Nährstoffzufuhr für gesunde Erwachsene, da insbesondere bei eingeschränkter Nierenfunktion eine erhöhte Vitamin-C-Zufuhr zu erhöhten Serum-Oxalatspiegeln führt, die ihrerseits die Gefahr von Gefäßkomplikationen in sich bergen. Der Gehalt an Vitamin B6, Nicotinamid, Folsäure und Biotin liegt über den Empfehlungen der DGE, da bei Niereninsuffizienz ein er-höhter Bedarf an diesen Vitaminen besteht. Eine Substitution von Vitamin B12 ist insbesondere bei eiweißreduzierten vegetabilen Diä-ten im präterminal niereninsuffizienten Stadium nötig, da durch den Verzicht Vitamin-B12reicher tierischer Nahrungsmittel üblicherweise ein Zufuhrdefizit auftritt. Unter

Hämodialysetherapie ist insbesondere bei Verwendung von Dialysatoren mit hoher B12-

Clearance (High-flux-Dialysatoren) eine Vitamin-B12-Substitution sinnvoll. Ein Dragee Ren-ovit deckt den täglichen Vitamin-B12-Bedarf. Originalpackung mit 100 Dragees (OP) DM 24,81 (AV inkl. MwSt). Erhältlich in Apotheken. Weitere Informationen von:

Nephro-Medica Sudetenstraße 20 D-6307 Linden (BRD) Tel. (06403)72335 Fax (06403) 72764

Hochdosiert bringt doppelten Vorteil: $\alpha$-Liponsäure bei diabetischer Polyneuropathie

Viele Patienten mit diabetischer Polyneuropathie sind multimorbid und müssen täglich viele

Tabletten einnehmen. Für eine verbesserte Patientencompliance und zugleich preisgünstigere

Therapie gibt es jetzt Thioctacid 200 (200 mg $\alpha$-Liponsäure) als Filmtablette auf dem Markt. Mit Thioctacid 200 wird der Therapieerfolg vereinfacht: Nur noch zweimal täglich, morgens und abends, je eine Thioctacid 200 (Hersteller: ASTA Medica, Frankfurt/M.).

Die diabetische Polyneuropathie, eine der schwersten Begleiterkran-kungen des Diabetes mellitus, wird mit Thioctacid positiv beeinflußt, indem gestörte Nervenfunktionen wiederhergestellt werden. Eine hochdosierte Langzeitbehandlung mit Thioctsäure - eine natürlich vorkommende, biologisch aktive Substanz - ist wissenschaftlich gut dokumentiert und 
einer hochdosierten Vitamin-B-Kombination signifikant überlegen. Für einen schnellen Wirkungseintritt wird eine parenterale Initialtherapie mit einer Infusion täglich (500 $\mathrm{mg}$ ) über zwei bis vier Wochen empfohlen, die Erhaltungstherapie beträgt täglich $400 \mathrm{mg}$ (Filmtabletten). Thioctacid ist auch als 2, 4 und $10 \mathrm{ml}$ mit 50,100 und $250 \mathrm{mg}$ Thioctsäure Injektionslösung erhältlich.

ASTA Pharma AG

Weismüllerstraße 45 D-6000 Frankfurt/Main 1

Indikationserweiterung ONKHÄS $®$ «Störungen der Mikrozirkulation»

Für die niedermolekulare Hydroxytheylstärke-Lösung ON-KOHÄS® (HES 40000/0,5 6\%)

wurden die bisherigen Anwendungs-gebiete, Hämodilution und Priming der Herz-Lungen-

Maschine, um die Indikation «Störungen der Mikrozirkulation» ergänzt. Im Zusammenhang mit dieser Indikationserweiterung erschien die neueste Ausgabe der Informationsreihe «B. Braun Melsungen informiert» ONKOHÄS ${ }^{\circledR}$ zur Verbesserung der Mikrozierkulation Nr. 15/1991. In übersichtlicher Form werden die Ergebnisse experimenteller und klinischer Untersuchungen dargestellt und die Vorteile von z.B. aku-ter zerebraler Ischämi und arterieller Verschlußkrankheit mit ONKOHÄS $®$ beschrieben.

Die Broschüre richtet sich an alle rheologisch interessierten Ärzte und Phramazeuten und kann angefordert werden bei:

B. Braun Melsungen AG Geschäftsbereich Pharma Postfach 110 und 120 D-3508 Melsungen 